\title{
Lumbar Facet Cyst Causing S1 Radiculopathy with Concomittent Acute on Chronic Cervical Prolapse Intervertebral Disc, a Rare Case Report
}

\author{
Tan Wei How, Ed. Simor Khan \\ KPJ Healthcare University College, Nilai, Malaysia \\ Email: tanweihow@yahoo.com.my
}

How to cite this paper: How, T.W. and Khan, Ed.S. (2021) Lumbar Facet Cyst Causing S1 Radiculopathy with Concomittent Acute on Chronic Cervical Prolapse Intervertebral Disc, a Rare Case Report. Journal of Biosciences and Medicines, 9, 59-66.

https://doi.org/10.4236/jbm.2021.97008

Received: June 3, 2021

Accepted: July 12, 2021

Published: July 15, 2021

Copyright $\odot 2021$ by author(s) and Scientific Research Publishing Inc. This work is licensed under the Creative Commons Attribution International License (CC BY 4.0).

http://creativecommons.org/licenses/by/4.0/ (c) (i) Open Access

\begin{abstract}
Tandem spinal stenosis is described as concurrent symptomatic cervical and lumbar spinal stenosis. The clinical presentation includes neurogenic claudication, gait disturbance, myelopathy and polyradicuopathy in both upper and lower limbs. A 43-year-old female presented with predominant low back pain with right $\mathrm{S} 1$ radiculopathy leading to diagnosis of synovial facet cyst of lumbar spine. She was managed surgically after medical treatment failed. After 1 week post operatively, she presented with severe neck pain with left radiculopathy. MRI revealed acute on chronic cervical prolapsed intervertebral disc, cervical decompression surgery proceeded. Post operative improvement was noted on follow up. We report a case of tandem spinal stenosis, which both of the pathologies were managed with endoscopic approach.
\end{abstract}

\section{Keywords}

Endoscopic Cervical Discectomy, Prolapse Intervertebral Disc, Facet Cyst, Radiculopathy, Minimally Invasive Spine Surgery

\section{Introduction}

Synovial facet cyst is an abnomal fluid-filled lesion of the spine that often associated with degenerative changes of the spine [1]. They are commonly seen in lumbar spine, rarely in cervical and thoracic spine [2]. In lumbar spine, $60 \%$ to $89 \%$ occur at L4/L5 level, $14 \%$ at L3/L4 level and 12\% at L5/S1 level [3]. L4/L5 level is the most mobile segment at the lumbar spine which predisposing to facet joint osteoarthritits and cyst formation [4]. The pathogenesis is poorly understood, but they are often associated with spinal trauma, microinstability and de- 
generative facet disease. Spinal facet cysts are usually asymptomatic and incidentally found on MRI, however they may present with back pain, radicular pain, neurologic claudication and rarely with cauda equine syndrome and myelopathy [5].

A herniated cervical dics is one of the most common causes of neck pain and upper limb radiculopathy as a result of direct impingement of nerve roots and asociated with inflammatory processes. Anterior cervical discectomy and fusion $(\mathrm{ACDF})$ is a common surgical procedure for cervical spine surgery. In recent decades, new techniques developed with the advancement of technology allowed minimally invasive surgery to achieve similar clinical outcomes compared with conventional procedures. This procedure was described by Hijikata [6] and Kambin [7], who introduced the concept of percutaneous lumbar discectomy, while the first description of the percutaneous endoscopic cervical discectomy (PECD) was reported in 1989 [8]. PECD has shown good clinical outcomes with low rate of complications and now becoming more popular. We report a case with double pathology of the spine which was treated by endoscopic approach with good result.

\section{Case Report}

A 43 year old female presented with low back pain with right lower limb radiculopathy pain for 1 year duration. Informed consent has been obtained from patient to report the case. Initially she was treated as lumbar prolapsed intervertebral disc, was on regular physiotherapy and pain management. It increased in severity for the last 3 months and affecting her daily activities. Clinically, she has no neurological deficits. Straight leg raising test was negative for both lower limbs.

Plain lumbosacral $\mathrm{x}$ ray (Figure 1(a) and Figure 1(b)) showed mild degenerative changes of lumbar spine. MRI of lumbar spine revealed an extradural cystic lesion arising from the right side L5S1 facet and causing compression of the right S1 nerve root (Figure 2(a) and Figure 2(b)).

In view of conservative management failed, patient keen to proceed with surgery. She underwent resection of the facet cyst through endoscopic interlaminar approach. Intra-operatively, the facet cyst was not found but the thecal sac and right L5 nerve root was under tension. Hence we performed laminotomy over superior lamina of the facet joint. Post laminotomy, the right L5 nerve root was free of tension and pulsating.

Post operatively, the patient's symptoms of back pain and radiculopathy improved. She was able to mobilise with full weight bearing. She was discharge home on day 2 post operatively. Post surgery MRI of lumbar spine (Figure 3(a) and Figure 3(b)) revealed the facet cyst was removed and spinal canal over right side more spacious compared to the previous MRI.

1 week post-operative, patient came to clinic complaining of severe neck pain (pain score 9/10) and radiating to left upper limb, whereas the low back pain was much more improve compared to pre-operative and S1 radiculopathy subsided. 
On further history, she had neck discomfort for 1 year prior to this current episode. Clinically neurology of the both upper limbs was normal. Myelopathy signs were negative.

Cervical X ray (Figure 4) revealed loss of cervical lordosis and MRI (Figure 5(a) and Figure 5(b)) showed big herniated disc over C5C6 level at the left paracentral region compressing $\mathrm{C} 6$ traversing nerve root.

Patient underwent endoscopic discectomy of C5C6 level. Intra-operatively, there were 2 loose fragments of disc material over the shoulder (Figure 6) and axillary region (Figure 7) of $\mathrm{C} 6$ nerve root. After removal the 2 disc materials, the nerve root was noted to be inflammed but free of tension and pulsating (Figure 8).

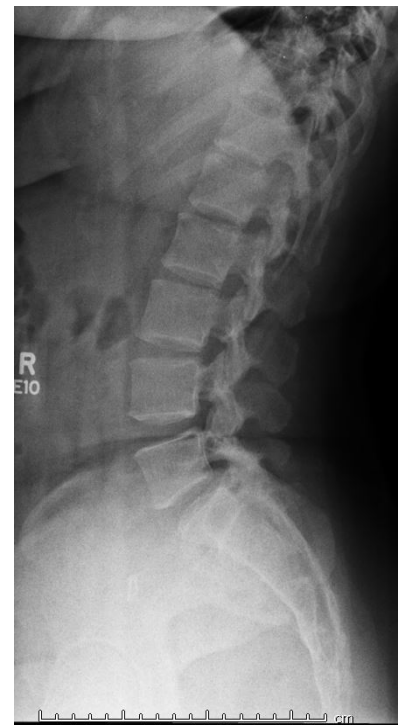

(a)

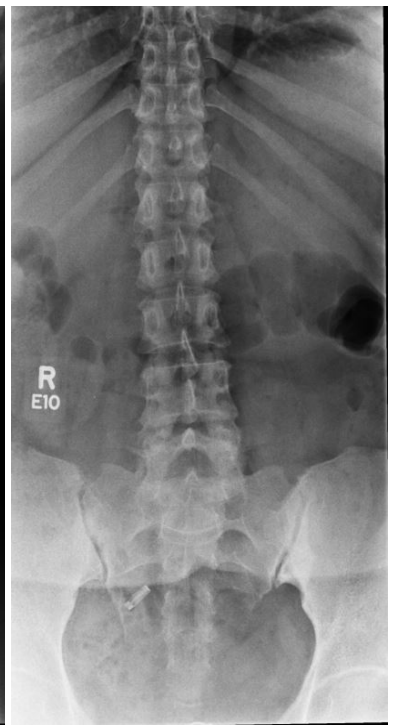

(b)

Figure 1. Lumbosacral $\mathrm{x}$ ray showed mild degenerative changes of lumbar spine.

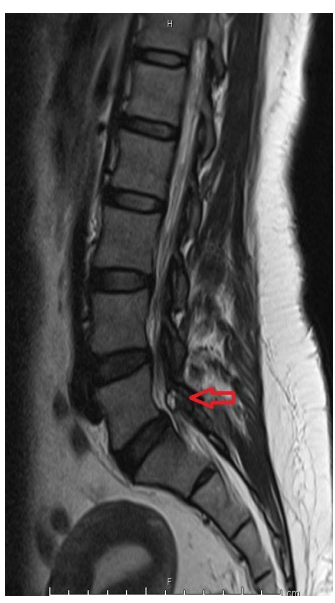

(a)

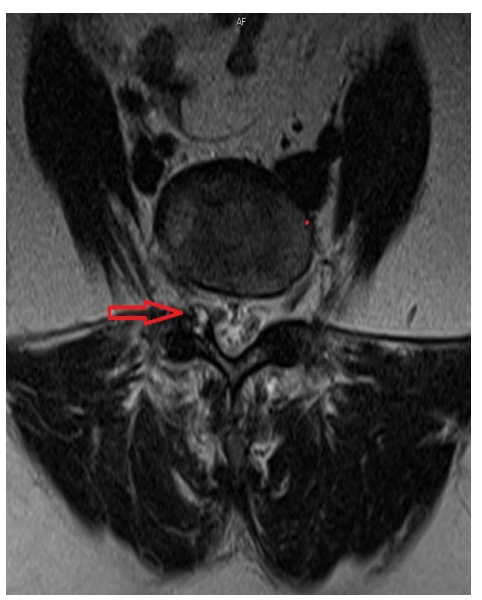

(b)

Figure 2. MRI revealed an extradural cystic lesion arising from the right side L4/L5 facet and causing compression of the right L5 nerve root. 


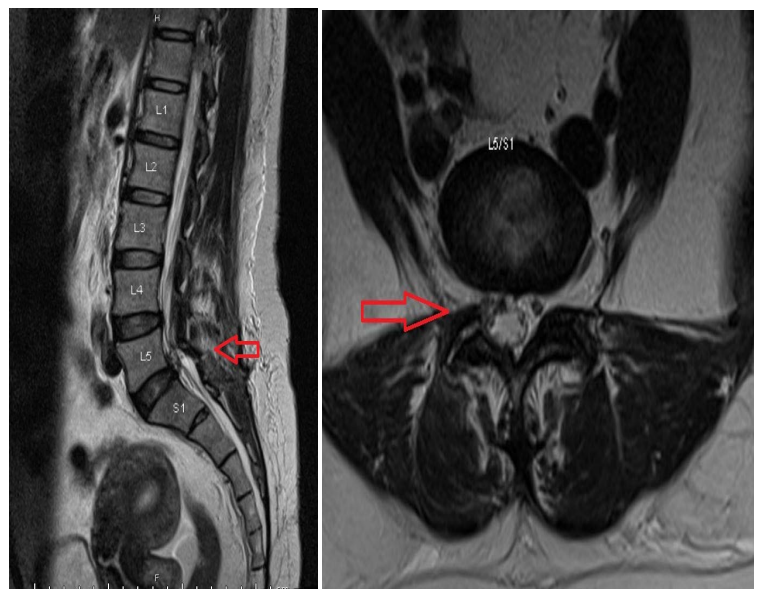

(a)

(b)

Figure 3. Post operative MRI revealed the facet cyst has been removed and spinal canal over right side more spacious compared to the previous MRI.

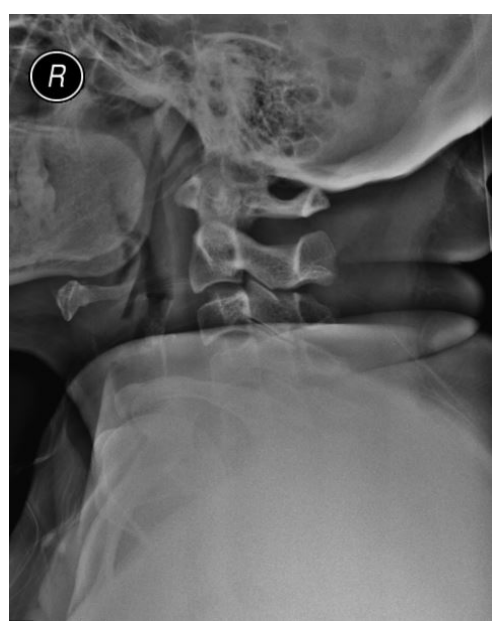

Figure 4. Cervical $\mathrm{x}$ ray showed loss of lumbar lordosis (visualised from $\mathrm{C} 1$ to $\mathrm{C} 5$ ).

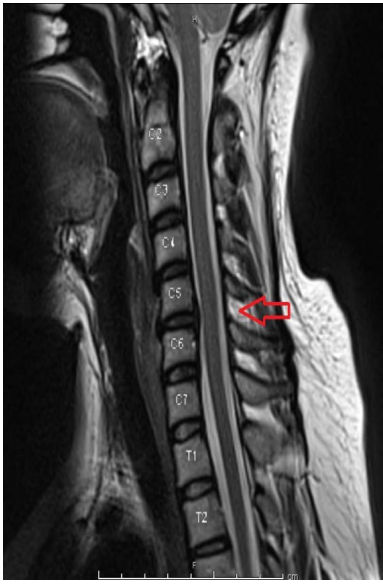

(a)

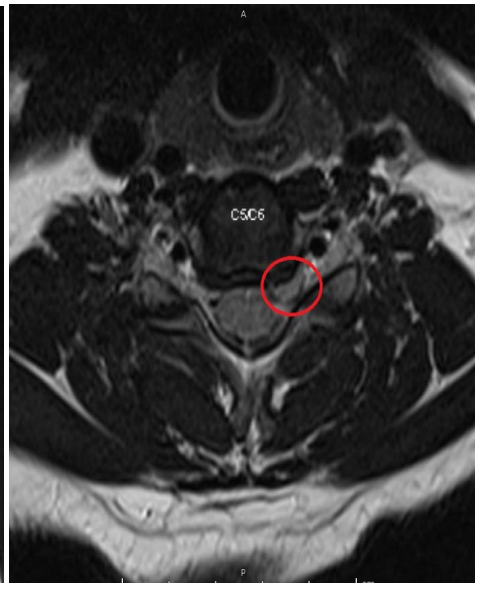

(b)

Figure 5. MRI cervical spine showed big herniated disc over C5C6 level at the left paracentral region compressing $\mathrm{C} 6$ traversing nerve root. 


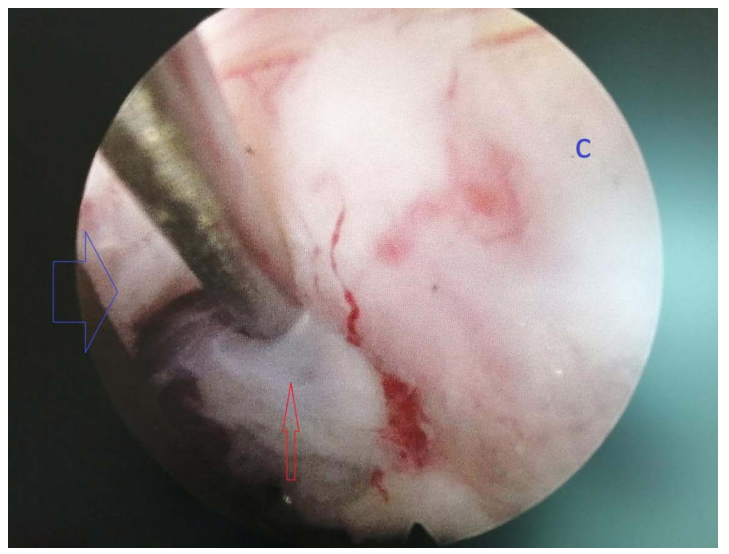

Figure 6. A large loose fragment of disc material (red arrow) was found at the shoulder region of C6 nerve root (blue arrow). C indicates cranial site of the spinal cord.

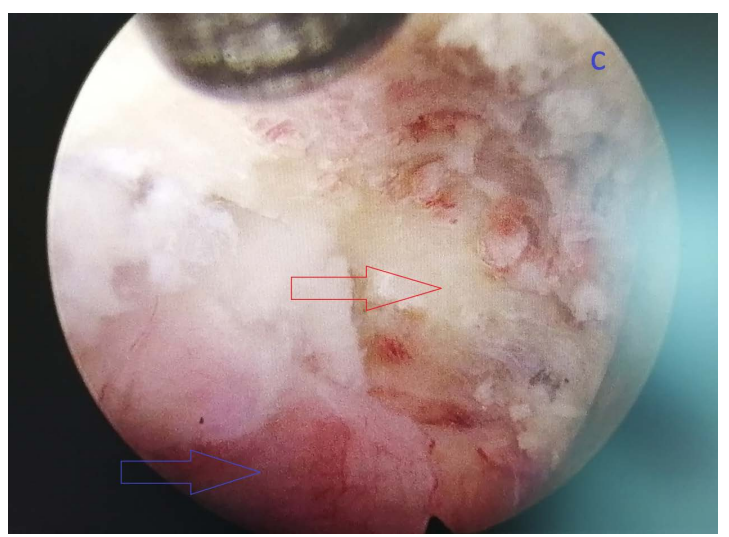

Figure 7. Another large loose fragment of disc material (red arrow) was found at the axillary region of C6 nerve root (blue arrow). $\mathrm{C}$ indicates cranial site of the spinal cord.

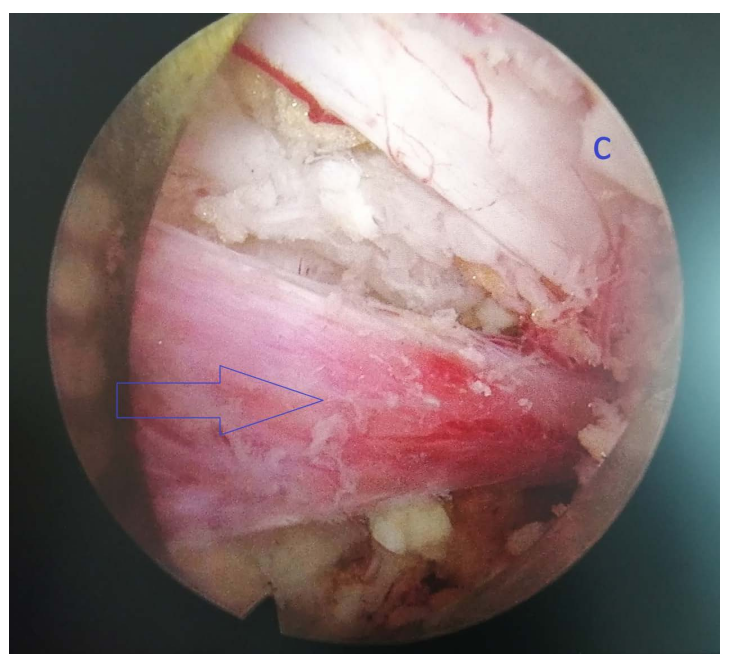

Figure 8. The C6 nerve root (blue arrow) was inflammed but free of tension and pulsating. $\mathrm{C}$ indicates cranial site of the spinal cord. 
Post operatively, the neck pain and left radiculopathy improving. She was able to ambulate well. She was discharged well on day 2 post operatively. Subsequent 3 months follow up, she was well and remain asymptomatic.

\section{Discussion}

Synovial facet cyst is rare and usually asymptomatic, however they may present with back pain, radicular pain, neurogenic claudication and rarely cauda equine syndrome and myelopathy [5]. The most common cause is herniated nucleus pulposus (HNP). $92 \%$ of the HNP occur in the lumbar spine, $5 \%$ in the thoracic spine, and only $3 \%$ in cervical spine [6]. Other differential diagnosis for non discogenic sciatica includes lumbar herpes zoster, lumbar instability, nerve root schwannoma, sciatic neuritis, facet cyst and hyperthrophy, piriformis syndrome, and intrapelvic mass or coxarthrosis.

The differential diagnosis of soft tissue mass in spinal canal includes extruded or sequested disc fragment, facet cyst, metastatic tumor, meningioma, schwannoma, neurofibroma with cystic degeneration, arachnoid cyst, perineural cyst and dermoid cyst.

Non-surgical treatment can be considered as the first therapeutic option, especially in patients without neurological deficit as spontaneous regression of facet cysts are possible. The non-surgical management consists of analgesia, physiotherapy, bracing, facet injection and cyst aspiration. CT guided cyst rupture can be consider before proceed to laminectomy with decompression and cyst excision. The recurrent rate after cyst rupture is high, approximately $39 \%$ of patients require second surgical intervention. In the case of spinal instability, instrumentation spinal fusion surgery can be performed.

As in our case, facet cysts can be effectively and safely excised with minimally invasive surgical techniques. MIS approach decreases soft tissue injury, blood loss, length of incision, resulting in earlier ambulation and shorten hospital stay. In addition, MIS minimizes disruption of ligamentous and bony structures and could decrease the risk of progressive instability and the need for fusion [9]. The recurrence rate for facet cyst is about $3 \%$ after excision and decompression.

Anterior cervical discectomy and fusion is commonly use for treating cervical PID. This procedure has demonstrated to be safe, effective, and associated with high fusion rate [10]. However, some complications has been reported such as dysphagia, postoperative haematoma, unilateral recurrent laryngeal nerve palsy, cerebrospinal fluid leakage, accidental esophageal perforation, worsening of pre-existing symptoms (radiculopathy or myelopathy), temporary unilateral Horner syndrome, implant related failure, superficial surgical wound infection, adjacent segment disease, pseudoarthrosis and other graft-related problems [11]. Percutaneous endoscopic cervical discectomy (PECD) becoming more popular because this technique is capable to achieve similar clinical outcomes compared with conventional procedures but with the advantages of lesser tissue damage and reduced blood loss, hence resulted in shorter the hospital stay and early 
functional recovery [12].

There are two ways to perform PECD: anterior approach and posterior approach which is depends on the localization of the herniated disc. The aim of PECD is the decompression of the neural elements (spinal cord or exiting nerve root) under direct visualization through a percutaneous endoscopic approach [13]. Removal of central, paracentral and foraminal soft disc herniations can be done by PECD. Therefore, PECD is becoming more popular and considered as an alternative to ACDF, total disc replacement and posterior microdiscectomy for the treatment of cervical disc herniation [14]. As in our case, both of the lumbar facet cyst and cervical disc herniation were treated with endoscopic technique and patient has good post surgery outcome.

\section{Conclusion}

Endoscopic techniques are can be effective in both cervical and lumbar spine on proper selected patients with good indication and location pathology, has shown good clinical outcomes with low rate of complications.

\section{Conflicts of Interest}

The authors declare no conflicts of interest regarding the publication of this paper.

\section{References}

[1] Kurz, L.T., Garfin, S.R., Unger, A.S., Thorne, R.P. and Rothman, R.H. (1985) Intraspinal Synovial Cyst Causing Sciatica. Journal of Bone and Joint Surgery, 67, 865-871. https://doi.org/10.2106/00004623-198567060-00006

[2] Freidberg, S.R., Fellows, T., Thomas, C.B., et al. (1994) Experience with Symptomatic Spinal Epidural Cysts. Neurosurgery, 34, 989-993.

https://doi.org/10.1227/00006123-199406000-00006

[3] Salmon, B.L., Deprez, M.P., Stevenaert, A.E. and Martin, D.H. (2003) The Extraforaminal Juxtafacet Cyst as a Rare Cause of L5 Radiculopathy: A Case Report. Spine, 28, E405-E407. https://doi.org/10.1097/01.BRS.0000085101.37990.4C

[4] Hsu, K.Y., Zucherman, J.F., Shea, W.J. and Jeffrey, R.A. (1995) Lumbar Intraspinal Synovial and Ganglion Cysts (Facet Cysts): Ten-Year Experience in Evaluation and Treatment. Spine, 20, 80-89. https://doi.org/10.1097/00007632-199501000-00015

[5] Janjua, M.B., Smith, M.L., Shenoy, K., et al. (2017) Thoracic Juxtafacet Cyst (JFC): A Cause of Spinal Myelopathy. Journal of Spine Surgery, 3, 294-299.

https://doi.org/10.21037/jss.2017.06.12

[6] Epstein, N.E., Syrquin, M.S., Epstein, J.A. and Decker, R.E. (1990) Intradural Disc Herniations in the Cervical, Thoracic, and Lumbar Spine: Report of Three Cases and Review of the Literature. Journal of Spinal Disorders, 3, 396-403.

[7] Hijikata, S. (1989) Percutaneous Nucleotomy: A New Concept Technique and 12 Years Experience. Clinical Orthopaedics and Related Research, 238, 9-23. https://doi.org/10.1097/00003086-198901000-00003

[8] Kambin, P. and Sampson, S. (1986) Posterolateral Percutaneous Suction-Excision of Herniated Lumbar Intervertebral Discs: Report of Interim Results. Clinical Orthopaedics and Related Research, 207, 37-43. 
https://doi.org/10.1097/00003086-198606000-00008

[9] Tajima, T., Sakamoto, H. and Yamakawa H. (1989) Diskectomy Cervicale Percutanee. Revolution Medicines Orthopedics, 17, 7-10.

[10] Fraser, J.F. and Hartl, R. (2007) Anterior Aproaches to Fusion of the Cervical Spine: A Mataanalysis of Fusion Rates. Journal of Neurosurgery, 6, 298-303. https://doi.org/10.3171/spi.2007.6.4.2

[11] Fountas, K.N., Kaosalaki, E.Z., Nikolakakos, L.G., et al. (2007) Anterior Cervical Discectomy and Fusion Associated Complications. Spine, 32, 10-17.

[12] Synder, L.A., O’Toole, J., Eichholz, K.M., et al. (2014) The Technological Development of Minimally Invasive Spine Surgery. BioMed Research International, 2014, Article ID: 293582. https://doi.org/10.1155/2014/293582

[13] Ahn, Y. (2016) Percutaneous Endoscopic Cervical Discectomy Using Working Channel Endoscopes. Expert Review of Medical Devices, 13, 601-610. https://doi.org/10.1080/17434440.2016.1180245

[14] Lee, S.H., Lee, J.H., Choi, W.C., et al. (2007) Anterior or Minimally Invasive Approaches for the Cervical Spine. Orthopedic Clinics of North America, 38, 327-337. https://doi.org/10.1016/j.ocl.2007.02.007 